\title{
FUNGAL TRANSFORMATION OF OFLOXACIN AND ENROFLOXACIN
}

\author{
I.A. PARSHIKOV ${ }^{1}$ AND F.M. KHASAEVA ${ }^{2}$ \\ ${ }^{1}$ Institute of Applied Mechanics, Russian Academy of Sciences, Moscow, Russia \\ ${ }^{2}$ Department of Microbiology of Kabardino-Balkarian State Agrarian University of V.M. Kokov, \\ Nalchik, Russia
}

(Received 6 September, 2017; accepted 10 Novemebr, 2017)

Key words : Biotransformation, Enrofloxacin, Ofloxacin, Rhizoctonia solani, Fungi

\begin{abstract}
Absrtact- The ability of Rhizoctonia solani VKM F-942 to regioselective metabolize the fluoroquinolones ofloxacin and enrofloxacin was investigated. The fungus was grown in sucrose/peptone broth at $28^{\circ} \mathrm{C}$, dosed with $100 \mu \mathrm{g} / \mathrm{mL}$ ofloxacin or enrofloxacin, and incubated with shaking for 18 days. The cultures were extracted with ethyl acetate, which was evaporated in vacuo. High-performance liquid chromatography showed that both drugs were transformed to single metabolites, which were identified by mass spectrometry and proton nuclear magnetic resonance spectrometry. The product from ofloxacin $(40.0 \%$ of the total peak area at $280 \mathrm{~nm})$ was ofloxacin $N$-oxide and the product from enrofloxacin $(14.4 \%$ of the total peak area at $280 \mathrm{~nm}$ ) was enrofloxacin $N$-oxide.
\end{abstract}

\section{INTRODUCTION}

The fluoroquinolones are synthetic antimicrobial agents that are active against a broad spectrum of pathogenic bacteria. Two of the widely used fluoroquinolones are ofloxacin and enrofloxacin; ofloxacin is used for treatment of various bacterial infections in humans (Monk and Campoli-Richards, 1987) but enrofloxacin is restricted to veterinary use (Brown, 1996). Both drugs are used in Japan to treat respiratory diseases of poultry (Nakamura, 1995).

Ofloxacin is transformed in experimental animals to ofloxacin $\mathrm{O}$-glucuronide, $\mathrm{N}$-desmethyl-ofloxacin, and ofloxacin $\mathrm{N}$-oxide (Sudo et al., 1986). Enrofloxacin is transformed in rats to enrofloxacin $O$-glucuronide and to desethyl-enrofloxacin (= ciprofloxacin) in several mammals (Heitzman, 1995; Mengozzi et al., 1996). In poultry, enrofloxacin metabolites are formed by deethylation and $N$ hydroxylation as well as by opening of the piperazine ring (Heitzman, 1995).

Although the transformation of ofloxacin by fungi has not been reported, cultures of wooddecaying fungi have been shown to convert enrofloxacin to $\mathrm{CO}_{2}$ and several other metabolites (Martens et al., 1996; Wetzstein et al., 1997). The fungus Mucor ramannianus transforms enrofloxacin to enrofloxacin $\mathrm{N}$-oxide, desethylene-enrofloxacin, and $N$-acetylciprofloxacin (Parshikov et al., 2000). We now have investigated the transformation of fluoroquinolones by another fungus, Rhizoctonia solani VKM F-942.

\section{MATERIALS AND METHODS}

Rhizoctonia solani VKM F-942 was from the AllRussian Microorganism Collection and maintained on agar slants (Modyanova et al., 1999; Parshikov et al., 1999; Khasaeva et al., 2016a,b). The mycelium was scraped from the surface of the agar, suspended in $5 \mathrm{~mL}$ of sterilized water, and used to inoculate $500 \mathrm{ml}$ flasks. Each flask contained $100 \mathrm{~mL}$ of a medium containing (per liter): $30.0 \mathrm{~g}$ sucrose, $5.0 \mathrm{~g}$ peptone, $3.0 \mathrm{~g} \mathrm{NaCl}$, $3.0 \mathrm{~g} \mathrm{NaNO}_{3}, 5.0 \mathrm{~g} \mathrm{KH}_{2} \mathrm{PO}_{4^{\prime}} 0.5$ $\mathrm{g} \mathrm{MgSO}_{4} 7 \mathrm{H}_{2} \mathrm{O}, 0.5 \mathrm{~g} \mathrm{KCl}, 0.1 \mathrm{~g} \mathrm{FeSO}_{4^{\prime}} 1 \mathrm{mg} \mathrm{MnSO}_{4^{\prime}}$ and $1000 \mathrm{~mL}$ deionized water. The $\mathrm{pH}$ was adjusted to 5.0. Cultures were grown for 2 days on a rotary shaker at $28^{\circ} \mathrm{C}$ with shaking at $180 \mathrm{rpm}$.

Ofloxacin and enrofloxacin were purchased from Sigma Chemical Co. These compounds were dissolved (at $10 \mathrm{mg} \mathrm{mL}^{-1}$ ) in $20 \mathrm{mM}$ aqueous $\mathrm{KOH}$ and filter-sterilized; $1.0 \mathrm{~mL}$ was added to each flask to make the final concentrations $249 \mu \mathrm{M}$ ofloxacin and $253 \mu \mathrm{M}$ enrofloxacin. After dosing, the cultures

Corresponding author's email: igorallp@gmail.com 
were incubated for an additional 18 days at $28^{\circ} \mathrm{C}$ with shaking at $180 \mathrm{rpm}$.

The mycelia were harvested by using filter paper in a Büchner funnel and then extracted with three equal volumes of ethyl acetate, which was dried over anhydrous sodium sulfate and evaporated in vacuo. The residues were dissolved in methanol: acetonitrile: acetic acid (10:10:2) for analysis. Extracts were analyzed and metabolites were purified by high-performance liquid chromatography (HPLC), using a Phenomenex Prodigy ODS-3 column $(10 \times 250 \mathrm{~mm})$. The mobile phase components were solvent A (water:methanol, 90:10) and solvent B (water:methanol, 10:90); acetic acid $\left(2 \mathrm{~mL} \mathrm{~L}^{-1}\right)$ was added to both components and the $\mathrm{pH}$ was adjusted to 3.0. The mobile phase (flow rate $=3.0 \mathrm{~mL} \mathrm{~min}^{-1}$ ) was a gradient increasing from $10 \%$ to $95 \%$ solvent B over 20 min (Parshikov et al., 1999). Metabolite concentrations were estimated from the HPLC peak areas at $280 \mathrm{~nm}$.

Liquid chromatography/electrospray ionization mass spectrometry (LC/ESI MS) was performed with a Hewlett-Packard 1090L/M HPLC system and a Hewlett-Packard 5989B quadrupole mass spectrometer operated using positive-ion electrospray ionization (ESI) with in-source collision-induced dissociation (CID). Components were resolved using a Phenomenex Prodigy ODS3 HPLC column $(2.0 \times 250 \mathrm{~mm})$. The mobile phase (flow rate $=0.2 \mathrm{~mL} / \mathrm{min}$ ) was a linear $40-\mathrm{min}$ gradient from 5\% acetonitrile / $95 \%$ water to $95 \%$ acetonitrile / $5 \%$ water in $20 \mathrm{~min}$ with constant $0.1 \%$ formic acid.

Proton nuclear magnetic resonance (NMR) spectral analyses were performed at $500 \mathrm{MHz}$ as previously described (Parshikov et al., 1999) except that the compounds were dissolved in deuterated methanol.

\section{RESULTS}

HPLC analysis of the ethyl acetate extract from cultures of Rh. solani VKM F-942 dosed with enrofloxacin showed that enrofloxacin eluted from the HPLC column at $10.0 \mathrm{~min}$ and a metabolite at $11.6 \mathrm{~min}$. After 18 days, as shown by the integrated peak area $\left(A_{280}\right)$ for enrofloxacin, $85.6 \%$ of the starting material remained.

The enrofloxacin metabolite had a yield of $14.4 \%$ of the total $A_{280}$ and a UV absorption spectrum with $\lambda_{\text {max }}=274,319$ and $331 \mathrm{~nm}$. The positive-ion ESI mass spectrum included ions at $\mathrm{m} / \mathrm{z} 376[\mathrm{M}+\mathrm{H}]^{+}, 360$
$[\mathrm{M}+\mathrm{H}-\mathrm{O}]^{+}, 359[\mathrm{M}+\mathrm{H}-\cdot \mathrm{OH}]^{+}, 358\left[\mathrm{M}+\mathrm{H}-\mathrm{H}_{2} \mathrm{O}\right]^{+}, 344$ $\left[\mathrm{M}+\mathrm{H}-\mathrm{CH}_{3} \mathrm{OH}\right]^{+}, 315(100)\left[\mathrm{M}+\mathrm{H}-\cdot \mathrm{OH}-\mathrm{CO}_{2}\right]^{+}$, and $300\left[\mathrm{M}+\mathrm{H}-\mathrm{CH}_{3} \mathrm{OH}-\mathrm{CO}_{2}\right]^{+}$. The mass spectra are different from those published previously (Parshikov et al., 2000) because positive-ion ESI MS with in-source CID was used instead of regular ESI MS or MS/MS. The ${ }^{1} \mathrm{H}$ NMR data presented in Table 1 are virtually the same as those previously reported (Parshikov et al., 2000); the metabolite was dissolved in deuterated methanol instead of deuterium oxide. Based on the MS and NMR results, the metabolite (Fig. 1) was identified as enrofloxacin $N$-oxide.

HPLC analysis of the ethyl acetate extract from cultures of Rh. solani VKM F-942 dosed with ofloxacin showed that ofloxacin eluted from the HPLC column at $9.4 \mathrm{~min}$ and a metabolite at 11.4 min. After 18 days, as shown by the integrated peak area $\left(A_{280}\right)$ for ofloxacin, $60.0 \%$ of the starting material remained.

The ofloxacin metabolite had a yield of $40.0 \%$ of the total $A_{280}$ and a UV absorption spectrum with $\lambda_{\max }=296$ and $330 \mathrm{~nm}$. The positive-ion ESI mass spectrum included ions at $\mathrm{m} / \mathrm{z} 378[\mathrm{M}+\mathrm{H}]^{+}, 361$ $[\mathrm{M}+\mathrm{H} \cdot \cdot \mathrm{OH}]^{+}, 317(100)\left[\mathrm{M}+\cdot \mathrm{OH}-\mathrm{CO}_{2}\right]^{+}, 247$, and 246. The proton resonances for $\mathrm{H} 2$ and $\mathrm{H} 5$ in ${ }^{1} \mathrm{H}$ NMR spectrum had similar chemical shifts as those in other fluoroquinolones. The resonances for $\mathrm{H}_{\mathrm{a}} \mathrm{H}_{\mathrm{b}}$, and $\mathrm{H}_{\mathrm{c}}$ were assigned based on their chemical shifts, multiplicities, integration, and homonuclear

Table 1. ${ }^{1} \mathrm{H}$ NMR parameters for the metabolites ${ }^{\mathrm{a}}$ of ofloxacin and enrofloxacin produced by $R h$. solani VKM F-942

\begin{tabular}{|c|c|c|}
\hline Proton & $\begin{array}{l}\text { Ofloxacin } \\
N \text {-oxide }^{\mathrm{b}}\end{array}$ & $\begin{array}{c}\text { Enrofloxacin } \\
N \text {-oxide }\end{array}$ \\
\hline $\mathrm{H} 2$ & 8.78 & 8.84 \\
\hline H5 & 7.74 & 8.03 \\
\hline $\mathrm{H} 8$ & 7.71 & \\
\hline Piperazine a & $3.35,4.00$ & \\
\hline Piperazine b & $3.32,3.63$ & \\
\hline Piperazine $a+b$ & & $3.33,3.62-3.78$ \\
\hline $\mathrm{H}_{\mathrm{a}}$ & 1.53 & \\
\hline $\mathrm{H}_{\mathrm{b}}^{\mathrm{a}}$ & 4.72 & \\
\hline $\mathrm{H}_{\mathrm{c}}$ & $4.40,4.56$ & \\
\hline $\mathrm{H}_{\mathrm{d}}^{\mathrm{c}}$ & & 3.45 \\
\hline $\mathrm{H}_{\mathrm{e}}$ & 3.26 & 1.43 \\
\hline $\mathrm{H}_{\mathrm{f}}$ & & 3.77 \\
\hline $\mathrm{H}_{\mathrm{g}}$ & & $1.22,1.43$ \\
\hline
\end{tabular}


decoupling experiments. The piperazine $\alpha$ and $\beta$ resonances were assigned based on homonuclear decoupling and NOE experiments. The large downfield shifts of the piperazine $\beta$ resonances indicated the formation of an $\mathrm{N}$-oxide The ${ }^{1} \mathrm{H}$ NMR data are shown in Table 1. The metabolite (Fig. 1) was identified 'as ofloxacin $N$-oxide.

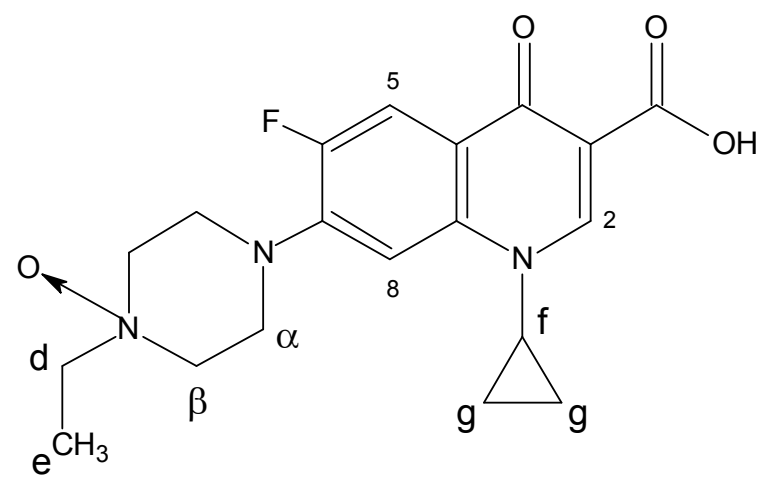

Enrofloxacin $N$-oxide<smiles>[2H]C1([2H])Oc2c(N3CCN(C)CC3)c(F)cc3c(=O)c(C(=O)O)cn1c23</smiles>

\section{Ofloxacin $N$-oxide}

Fig. 1. Structures of the enrofloxacin $N$-oxide and ofloxacin $\mathrm{N}$-oxide metabolites formed from ofloxacin and enrofloxacin by $R h$. solani VKM F942.

\section{DISCUSSION}

The biotransformation of fluoroquinolones that have an $\mathrm{N}$-alkyl substituent on the piperazine ring, such as ofloxacin and enrofloxacin, may proceed by different pathways in different organisms. In animals, such fluoroquinolones are metabolized at either the $N$-alkylpiperazine ring or the carboxyl group (Borner et al., 1990). For instance, ofloxacin, amifloxacin, difloxacin, fleroxacin, and pefloxacin are modified in mammals by $\mathrm{N}$-oxidation of the alkylpiperazine rings as well as by other reactions (Sudo et al., 1986; Carlucci, 1998).

Several pathways are also used in fungal bioconversions of fluoroquinolones. Fungi metabolize the piperazine ring by $\mathrm{N}$-oxidation, dealkylation, $\mathrm{N}$-acetylation, removal of two carbons, or total breakdown of the ring (Wetzstein et al., 1997; Parshikov, 2016; Parshikov, 2017). We have studied the transformation of fluoroquinolones by different strains of fungi, such as $M$. ramannianus $\mathrm{R}-56$ (Parshikov et al., 2000) and Rh. solani VKM F-942. The transformation of ofloxacin and enrofloxacin by $R h$. solani VKM F-942 involves a regioselective $N$ oxidation of the terminal nitrogen of the piperazine ring, as reported previously for the metabolism of enrofloxacin by M. ramannianus (Parshikov et al., 2000). Because the antibacterial activity of enrofloxacin $\mathrm{N}$-oxide is much less than that of enrofloxacin (Wetzstein et al., 2000), fungal Noxidation may reduce the antibacterial activity of fluoroquinolone residues in the environment.

\section{ACKNOWLEDGEMENT}

We thank for Institute of Applied Mechanics, Russian Academy of Sciences for financial support of this work.

\section{REFERENCES}

Borner, K., Borner, E., Hartwig, H. and Lode, H. 1990. HPLC of recent quinolone antimicrobials, p. 131-144 In: E. Reid, and I.D. Wilson, (Eds.) Analysis for Drugs and Metabolites, Including Anti-Infective Agents. Royal Society of Chemistry. Cambridge, UK

Brown, S.A. 1996. Fluoroquinolones in animal health. J. Vet. Pharmacol. Ther. 19 : 1-14.

Carlucci, C. 1998. Analysis of fluoroquinolones in biological fluids by high-performance liquid chromatography. J. Chromatogr. A. 812: 343-367.

Heitzman, R.J. 1995. Enrofloxacin, p. 31-44 In: Residues of Some Veterinary Drugs in Animals and Foods, monographs prepared by the 43rd meeting of the Joint FAO-WHO Expert Committee on Food Additives. Food and Agriculture Organization of the United Nations. Rome, Italy

Khasaeva, F.M., Parshikov, I.A. and Zaraisky, E.I. 2016a. Degradation of 2,6-Dimethylpyridine by Arthrobacter crystallopoietes. Ecology, Environment and Conservation. 18: 1673-1676.

Khasaeva, F.M., Parshikov, I.A. and Zaraisky, E.I. 2016b. Biodegradation of 4-methylpyridine by Àrthrobacter sp. Asian Journal of Microbiology, Biotechnology and Environmental Sciences. 22 : 75-77.

Martens, R., Wetzstein, H.G., Zadrazil, F., Capelari, M., 
Hoffmann, P. and Schmeer, N. 1996. Degradation of the fluoroquinolone enrofloxacin by wood-rotting fungi. Appl. Environ. Microbiol. 62: 4206-4209.

Mengozzi, G., Intorre, L., Bertini, S. and Soldani G. 1996. Pharmacokinetics of enrofloxacin and its metabolite ciprofloxacin after intravenous and intramuscular administrations in sheep. Am. J. Vet. Res. 57: 10401043.

Modyanova, L. V., Duduchava, M.R., Piskunkova, N.F., Grishina, G.V., Terentyev, P.B. and Parshikov, I.A. 1999. Microbial transformations of piperideine and pyridine derivatives [in Russian]. Khim. Geterotsikl. Soed. 35 : 649-655.

Monk, J.P. and Campoli-Richards, D.M. 1987. Ofloxacin. A review of its antibacterial activity, pharmacokinetic properties and therapeutic use. Drugs. 33 : 346-391.

Nakamura, S. 1995. Veterinary use of new quinolones in Japan. Drugs 49 : 152-158.

Parshikov, I.A., Freeman, J.P., Lay, J.O., Beger, R.D., Williams, A.J. and Sutherland, J.B. 1999. Regioselective transformation of ciprofloxacin to $\mathrm{N}$ acetylciprofloxacin by the fungus Mucor ramannianus. FEMS Microbiol. Lett. 177 : 131-135.

Parshikov, I.A., Freeman, J.P., Lay, J.O., Beger, R.D.,
Williams, A.J. and Sutherland, J.B. 2000. Microbiological transformation of enrofloxacin by the fungus Mucor ramannianus. Appl. Environ. Microbiol. 66 : 2264-2267.

Parshikov, I.A. 2016. Microbial Transformation of Nitrogen Containing Heterocycles. Primedia E-launch LLC, Dallas. $130 \mathrm{p}$.

Parshikov, I.A. 2017. Microorganisms in Chemistry of Nitrogenous Heterocycles. Primedia E-launch LLC, Dallas. $130 \mathrm{p}$.

Sudo, K., Okazaki, O., Tsumura, M. and Tachizawa, H. 1986. Isolation and identification of metabolites of ofloxacin in rats, dogs and monkeys. Xenobiotica 16: 725-732.

Wetzstein, H. G., Karl, W., Hallenbach, W., Himmler, T. and Petersen, U. 2000. Residual antibacterial activity of metabolites derived from the veterinary fluoroquinolone enrofloxacin, p. 2 In: Abstr. 100th Gen. Meet. Am. Soc. Microbiol. Los Angeles, USA

Wetzstein, H.G., Schmeer, N. and Karl, W. 1997. Degradation of the fluoroquinolone enrofloxacin by the brown rot fungus Gloeophyllum striatum: Identification of metabolites. Appl. Environ. Microbiol. 63: 4272-4281. 